\title{
Polymeric Graphitic Carbon Nitride Doped with CuO Dispersed on Dealuminated Clinoptilolite (CuO/HCP): Synthesis and Characterisation
}

\author{
Saheed Olalekan Sanni ${ }^{1}$ and Omoruyi Gold Idemudia ${ }^{2}$ \\ ${ }^{1}$ Department of Chemistry, Vaal University of Technology, Private Bag x021, Vanderbijlpark 1900, South Africa \\ ${ }^{2}$ Chemistry Department, University of Fort Hare, Private Bag x1314, Alice 5700, South Africa \\ Correspondence should be addressed to Saheed Olalekan Sanni; mosqit.saheed@gmail.com \\ and Omoruyi Gold Idemudia; oidemudia@ufh.ac.za
}

Received 9 December 2014; Accepted 23 January 2015

Academic Editor: Stefano Bellucci

Copyright (c) 2015 S. O. Sanni and O. G. Idemudia. This is an open access article distributed under the Creative Commons Attribution License, which permits unrestricted use, distribution, and reproduction in any medium, provided the original work is properly cited.

$\mathrm{CuO}$ dispersed on dealuminated clinoptilolite $(\mathrm{CuO} / \mathrm{HCP})$ and further doped with polymeric graphitic carbon nitride $(\mathrm{CuO} / \mathrm{HCP}-$ g- $\mathrm{C}_{3} \mathrm{~N}_{4}$ ) was synthesized through 2 facile routes: precipitation method for $\mathrm{CuO} / \mathrm{HCP}$ and impregnation through ultrasonication method for the hybrid composite material. The hybrid composite material crystalline phase, surface morphology, and structural and thermal properties were investigated by X-ray diffraction (XRD), scanning electron microscopy (SEM), energy-dispersive Xray analysis (EDAX), Fourier transform infrared spectroscopy (FTIR), and thermal analysis. The formation of the hybrid composite material was confirmed by XRD showing crystalline phase of $\mathrm{CuO}$ and $\mathrm{g}-\mathrm{C}_{3} \mathrm{~N}_{4}$ present on the surface of dealuminated clinoptilolite (HCP). SEM images analysis depicts no aggregation of the mixed metal oxide semiconductor nanoparticles at the center of HCP. The hybrid composite material, $\mathrm{CuO} / \mathrm{HCP}-\mathrm{g}-\mathrm{C}_{3} \mathrm{~N}_{4}$, with a good homogeneously dispersed metal oxide conductor having excellent catalytic activities has been synthesized.

\section{Introduction}

The development of efficient, sustainable, stable, and alternative novel titania based photocatalytic materials, with visible light absorption, has gained a lot of research interest. A host of new metal oxide semiconductor which found application in environmental remediation consisting of $\mathrm{CaIn}_{2} \mathrm{O}_{4}$ [1], $\mathrm{NaTaO}_{3}$ [2], $\mathrm{BaTi}_{4} \mathrm{O}_{9}$ [3], $\mathrm{InTaO}_{4}$ [4], $\mathrm{BiVO}_{4}$ [5-7], CdS [8], and $\mathrm{Bi}_{2} \mathrm{WO}_{6}$ [9] has been extensively studied as a new series of photocatalyst. Cupric oxide $(\mathrm{CuO})$, a p-type metal oxide semiconductor with a narrow band gap of $1.36 \mathrm{eV}$, that is inexpensive and nontoxic in nature, is another alternative metal oxide semiconductor used as $\mathrm{TiO}_{2}$ based photocatalyst. $\mathrm{CuO}$ has found huge potential application in optical electronics, gas sensing [10], field emission emitters [11], lithium ion batteries [12], photovoltaic materials, and catalytic material $[13,14]$. Studies revealed that the fabrication of $\mathrm{CuO}$ on mesoporous based material such as graphene [15], titania nanotubes [16], and clinoptilolite [17] results in strong interaction between $\mathrm{CuO}$ and these mesoporous materials. This interaction results in the efficient transfer of photogenerated electrons from $\mathrm{CuO}$ conduction band to the mesoporous material, which invariably suppress recombination rate of photogenerated electron-hole pairs. $\mathrm{CuO}$ presence on these mesoporous materials surface allows efficient charge separation and the mesoporous materials promote electron migration, which aids enhanced photocatalytic activities and water splitting effectively.

Polymeric graphitic carbon nitride $\left(\mathrm{g}-\mathrm{C}_{3} \mathrm{~N}_{4}\right)$, a "metal free" n-type metal oxide semiconductor with band gap of $2.8 \mathrm{eV}$, has shown immense properties for $\mathrm{H}_{2}$ or $\mathrm{O}_{2}$ evolution via water splitting and good chemical stability in photocatalysis $[18,19]$. Several studies have employed polymeric carbon nitride alone in degradation of organic contaminant [20] under visible light irradiation. Though inefficient separation of photogenerated electron-hole pairs impairs the potential 
application of g- $\mathrm{C}_{3} \mathrm{~N}_{4}$, several attempts have been carried out to improve overall performance of $\mathrm{g}-\mathrm{C}_{3} \mathrm{~N}_{4}$ for enhanced photocatalytic activities under visible light irradiation. The combination of $g-\mathrm{C}_{3} \mathrm{~N}_{4}$ with other novel metal oxide semiconductors, mesoporous material, and polymer or as a nanocomposite has greatly enhanced organic contaminant removal and $\mathrm{H}_{2}$ evolution in water splitting, respectively [20-22]. Studies have also showed the combination of different metal oxide semiconductors with distinct energy levels and dispersion of these mixed photocatalysts on these mesoporous materials surface assist in charge separation of electron-hole pair under visible light irradiation which enhances photocatalytic activity effectively [23-26].

Clinoptilolite (CP), a cheap and natural form of zeolite, has found wide application for the dispersion of nanoparticles due to its exceptional chemical composition [27, 28], ion exchange, and surface properties, and it is employed as our mesoporous material in this study. Dealuminated clinoptilolite (HCP) with large surface area acts as excellent support material to disperse metal oxide conductor [27, 28] which invariably facilitates movement of photogenerated electrons and efficient separation within the composite material. Presented here is the facile synthesis of $\mathrm{g}-\mathrm{C}_{3} \mathrm{~N}_{4}-\mathrm{CuO} /$ HCP composite material, and the structural, morphological, thermal, and optical properties of prepared composite were characterized using Fourier transform infrared (FTIR) spectroscopy, X-ray diffraction (XRD), scanning electron microscopy (SEM), energy dispersive spectroscopy (EDS), and thermal analysis. The photocatalytic reaction mechanism for the hybrid photocatalyst is also proposed, to throw some light on their potential application stability and photocatalytic activities on organic pollutants.

\section{Experimental}

2.1. Synthesis of Dealuminated Clinoptilolite (HCP), CuO/ $\mathrm{HCP}$, and $\mathrm{CuO} / \mathrm{HCP}-\mathrm{g}-\mathrm{C}_{3} \mathrm{~N}_{4}$. The preparation of dealuminated clinoptilolite (HCP) has been discussed and highlighted in our previous studies [27, 28]. For copper oxide dispersed on dealuminated clinoptilolite, stoichiometric amount of $\mathrm{CuCl}_{2}$ was added to ethanol solution and allowed to continue stirring; to this stirring solution HCP was later added. This was followed by the addition of an appropriate amount of oxalic acid solution (chelating agent) to precipitate $\mathrm{CuO}$ on the surface of HCP and the solution further subjected to heating at $80^{\circ} \mathrm{C}$ for $5 \mathrm{hr}$. The obtained homogenous solution was further filtered and washed well with ethanol and water mixture to remove any impurities present. The final product was air-dried in the oven overnight $\left(60^{\circ} \mathrm{C}\right)$ and further calcined at $300^{\circ} \mathrm{C}$ for $2 \mathrm{hr}$. The same preparation route was applied for $\mathrm{CuO}$ synthesis without the addition of HCP.

Metal free $\mathrm{g}-\mathrm{C}_{3} \mathrm{~N}_{4}$ were prepared by thermal calcination of thiourea placed inside cover alumina crucible in a muffle furnace, which was calcined to $550^{\circ} \mathrm{C}$ and the products were collected after the heated crucible was cooled to room temperature. Polymeric graphitic nitride doped with $\mathrm{CuO} / \mathrm{HCP}$ was prepared via a facile impregnation via ultrasonication route, by adding $\mathrm{CuO} / \mathrm{HCP}$ to $\mathrm{g}-\mathrm{C}_{3} \mathrm{~N}_{4}$ dissolved in ethanol solution and the mixture was further allowed to ultrasonicate for 30 minutes. The resulting solution was filtered and washed well with distilled water and ethanol to remove any impurities present in the hybrid composites. The material was dried in the oven at $80^{\circ} \mathrm{C}$ and stored in the dark before elucidation of physical and chemical properties.

2.2. Characterization of the Hybrid Composite Material. The surface morphology of the samples was examined using scanning electron microscopy equipped with an EDAX system for energy dispersive spectroscopic analysis, which was coated with a thin layer of gold film to avoid charging. Powder Xray diffraction patterns were examined using Bruker diffractometer AXS with Cuk $\alpha$ source. The bond vibrations were analyzed on Fourier transform infrared (FTIR) spectrophotometer (Perkin Elmer spectrum 400) and the FTIR spectra were in the range of $600-4000 \mathrm{~cm}^{-1}$. Thermogravimetric analysis (TGA) was carried out using Perkin Elmer STA 6000 thermal simultaneous analyzer at heating rate of $10^{\circ} \mathrm{C} / \mathrm{min}$ from 30 to $900^{\circ} \mathrm{C}$ under $19.8 \mathrm{~mL} / \mathrm{mins}$ in nitrogen purge stream.

\section{Results and Discussion}

3.1. Morphology and Elemental Properties. The surface morphology of $\mathrm{CuO}, \mathrm{CuO} / \mathrm{HCP}$, and $\mathrm{g}-\mathrm{C}_{3} \mathrm{~N}_{4}$ and the hybrid composite material $\left(\mathrm{CuO} / \mathrm{HCP}-\mathrm{g}-\mathrm{C}_{3} \mathrm{~N}_{4}\right)$ nanostructure were observed using scanning electron microscopy (SEM) at the same resolutions. The materials $\left(\mathrm{CuO}, \mathrm{g}-\mathrm{C}_{3} \mathrm{~N}_{4}\right.$, and $\mathrm{CuO} /$ $\mathrm{HCP}$ ) show partial particle aggregation or agglomeration as depicted in Figure 1, with very good homogeneous particle size and shape distribution within the texture of the materials synthesized. Dealuminated clinoptilolite acts as capping agent or stabilizer, which hampers excessive growth of the metal oxide semiconductors within the hybrid composite material. However, upon doping of $\mathrm{CuO} / \mathrm{HCP}$ on $\mathrm{g}-\mathrm{C}_{3} \mathrm{~N}_{4}$, the hybrid material displays partial agglomeration microstructure which is attributed to pure $\mathrm{CuO} / \mathrm{HCP}$ sparsely covering the surface of $\mathrm{g}-\mathrm{C}_{3} \mathrm{~N}_{4}$ within the hybrid composite material.

The different resolutions of $\mathrm{CuO} / \mathrm{HCP}-\mathrm{g}-\mathrm{C}_{3} \mathrm{~N}_{4}$ at alternative magnifications are also depicted in Figure 2(a), there exist partial agglomeration of the $\mathrm{CuO} / \mathrm{HCP}$ particle in contact with $\mathrm{g}_{-} \mathrm{C}_{3} \mathrm{~N}_{4}$ surface at the center at lower magnification (Figure 2(a)). There seems to be signs of small gaps in the $\mathrm{CuO} / \mathrm{HCP}-\mathrm{g}-\mathrm{C}_{3} \mathrm{~N}_{4}$ material which can facilitate its enhanced photocatalytic activity on organic contaminants, which is ascribed to an exceptional large surface area of HCP. The large surface area of HCP can facilitate mass transfer and also provides more activity sites for surface-dependent reactions that will aid photocatalytic process for organic contaminant breakdown. However, as the magnification increases as depicted in Figures 2(b) and 2(c), irregular morphology and agglomeration begins to appear within the hybrid composite material.

The EDAX analysis was employed to obtain the elemental composition of prepared photocatalyst material. From Figure 3 , the existence of doped $\mathrm{CuO} / \mathrm{HCP}$ within the framework of $\mathrm{CuO} / \mathrm{HCP}-\mathrm{g}-\mathrm{C}_{3} \mathrm{~N}_{4}$ is revealed with the composite 


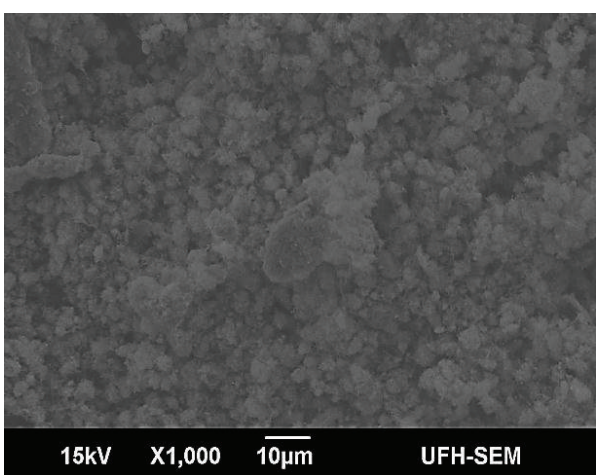

(a)

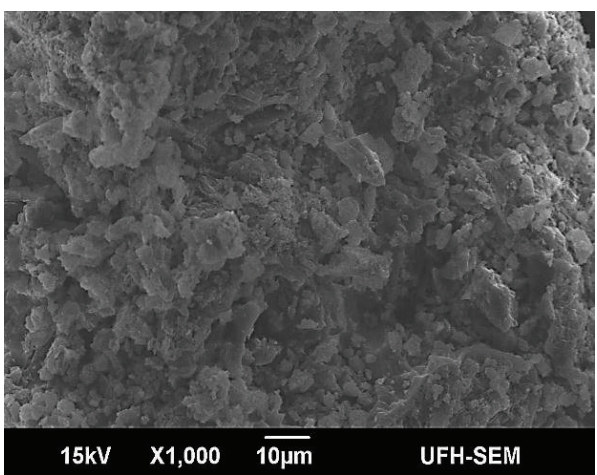

(c)

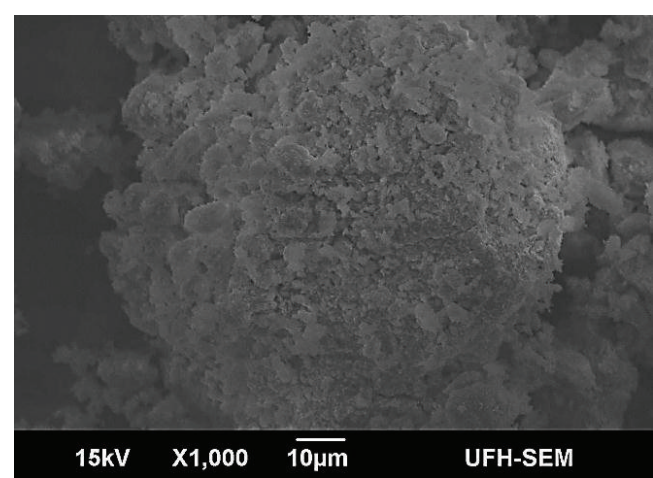

(b)

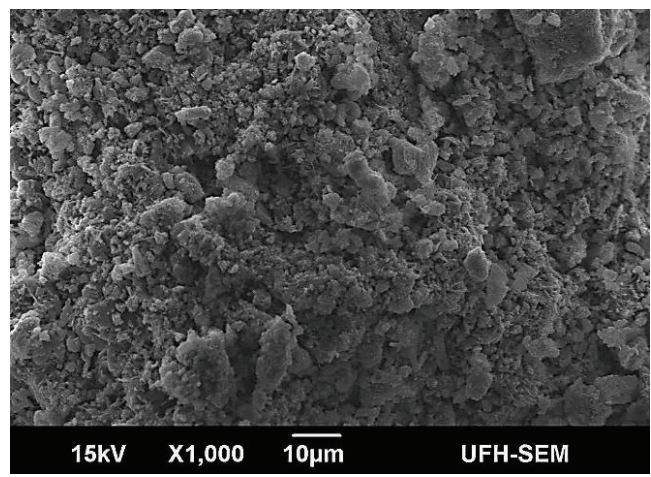

(d)

Figure 1: SEM images of (a) $\mathrm{CuO}$; (b) $\mathrm{CuO} / \mathrm{HCP}$; (c) g- $\mathrm{C}_{3} \mathrm{~N}_{4}$; and (d) $\mathrm{CuO} / \mathrm{HCP}-\mathrm{g}-\mathrm{C}_{3} \mathrm{~N}_{4}$.

material made up of $\mathrm{Cu}, \mathrm{O}, \mathrm{Si}, \mathrm{Al}, \mathrm{C}$, and $\mathrm{N}$. The elements $\mathrm{Si}$, $\mathrm{Al}$, and $\mathrm{O}$ are attributed to dealuminated clinoptilolite (HCP), $\mathrm{Cu}$ originated from the $\mathrm{CuO}$ material and $\mathrm{C}$, and $\mathrm{N}$ is attributed to polymeric graphitic carbon nitride present within the hybrid composite materials.

3.2. XRD Analysis. The XRD pattern of CuO/HCP-g- $\mathrm{C}_{3} \mathrm{~N}_{4}$ is shown in Figure 4 within the $2 \theta$ range of 5 to $60^{\circ}$. From the XRD data, characteristic peaks of $\mathrm{CuO}$ are observed at $2 \theta$ values of $32.50^{\circ}, 35.60^{\circ}, 38.80^{\circ}, 48.89^{\circ}, 56.50^{\circ}$, and $58.80^{\circ}[29,30]$ which are coherent with diffraction card peak (JCPDS 073-6234). The weak diffraction card peak of g$\mathrm{C}_{3} \mathrm{~N}_{4}$ (JCPDS 050-1250) is observed at $2 \theta$ value of $27.74^{\circ}$ which is tuned to characteristic interlayer stacking peak of conjugated aromatic systems in agreement with previous report [31]. The characteristic peaks observed at $9.83^{\circ}, 17.30^{\circ}$, $23.17^{\circ}, 27.50^{\circ}$, and $30.5^{\circ}$ are ascribed to the clinoptilolite (CP) diffraction card peak (JCPDS 025-1349) and depict that $\mathrm{CP}$ is the mesoporous material employed as our support layer for dispersion of our metal oxide semiconductors. From Figure 4, diffraction peaks of $\mathrm{CuO}$ are more pronounced than the peak of $\mathrm{g}-\mathrm{C}_{3} \mathrm{~N}_{4}$ in relation to SEM results in Figure 1. The result depicts the coexistence of $\mathrm{CuO}$ and $\mathrm{g}-\mathrm{C}_{3} \mathrm{~N}_{4}$ on the surface of dealuminated clinoptilolite; it is also worthy of note that the deposition of $\mathrm{CuO}$ and $\mathrm{g}-\mathrm{C}_{3} \mathrm{~N}_{4}$ on the surface of HCP did not destroy the clinoptilolite structure.
3.3. Structural Properties. The FTIR spectra of $\mathrm{g}-\mathrm{C}_{3} \mathrm{~N}_{4}$ in Figure 5 show consistent phase broad peak at 3195 and $3300 \mathrm{~cm}^{-1}$ due to stretching modes of amine unit and intermolecular hydrogen-bond interactions. Absorption peaks at $1638,1437,1376$, and $1273 \mathrm{~cm}^{-1}$ are ascribed to stretching modes of $\mathrm{CN}$ heterocycles $[32,33]$, while the characteristic peak of triazines unit is found at $825 \mathrm{~cm}^{-1}$ [32]. However, the FTIR spectrum of $\mathrm{CuO} / \mathrm{HCP}$ shows absorption peaks at 3487 to $3350 \mathrm{~cm}^{-1}$ ascribed to stretching vibrations of $-\mathrm{OH}$ units present in the zeolitic water. The $\mathrm{OH}$ units bending absorption peak of the zeolitic water are also pronounced at $1627 \mathrm{~cm}^{-1}$, while absorption bands at between 1100 and $916 \mathrm{~cm}^{-1}$ are ascribed to internal $\mathrm{Si}-\mathrm{O}(\mathrm{Si})$ and $\mathrm{Si}-\mathrm{O}(\mathrm{Al})$ stretch vibrations presented in the dealuminated clinoptilolite $[34,35]$. The absorption peak at $701 \mathrm{~cm}^{-1}$ is due to pseudolattice vibrations of $-\mathrm{OH}$ deformation unit and weak peaks of $\mathrm{CuO}$ at 1431 and $1395 \mathrm{~cm}^{-1}$ are observed in $\mathrm{CuO} / \mathrm{HCP}$. However, in the hybrid composite material, the weak peaks of $\mathrm{CuO}$ become broader $\left(1445 \mathrm{~cm}^{-1}\right)$ upon the dispersion of $\mathrm{CuO} / \mathrm{HCP}$ on $\mathrm{g}-\mathrm{C}_{3} \mathrm{~N}_{4}$. The stretching vibrations of $-\mathrm{OH}$ and amine units were reduced to 3470,3000 , and $3250 \mathrm{~cm}^{-1}$, respectively, while the bending $-\mathrm{OH}$ unit also reduces to $1620 \mathrm{~cm}^{-1}$ in the hybrid composite material. The absorption peak of stretching modes of $\mathrm{CN}$ heterocycles of $\mathrm{g}-\mathrm{C}_{3} \mathrm{~N}_{4}$ in the hybrid composite material is also increased to $1480 \mathrm{~cm}^{-1}$. However, the pseudo-lattice vibrations of $-\mathrm{OH}$ deformation 


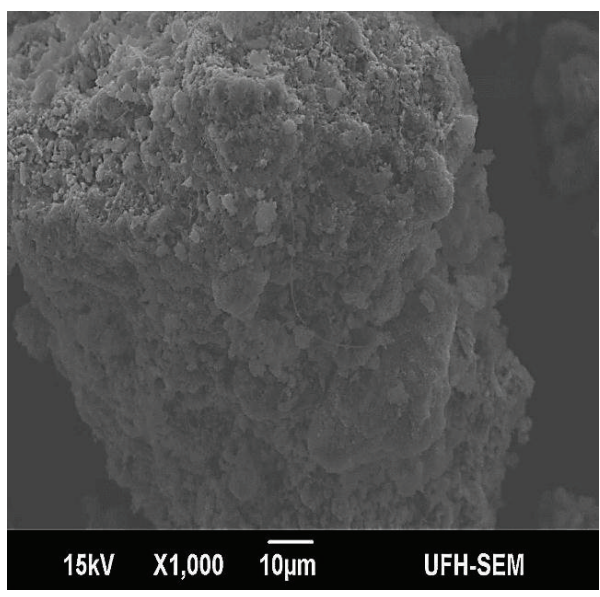

(a)

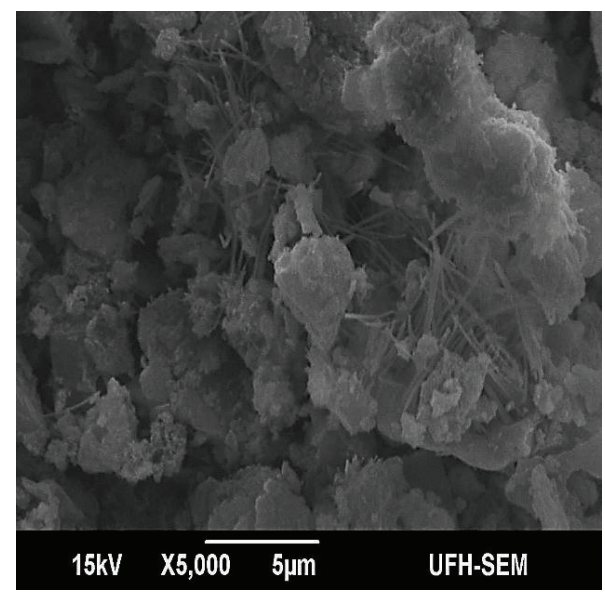

(b)

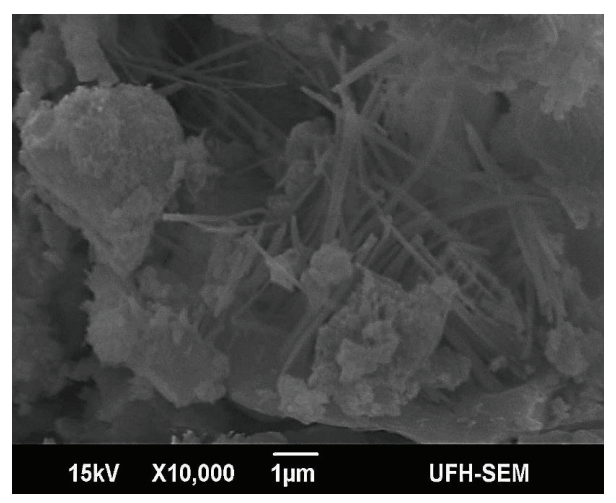

(c)

FIgURE 2: ((a)-(c)) SEM images of $\mathrm{CuO} / \mathrm{HCP}-\mathrm{g}-\mathrm{C}_{3} \mathrm{~N}_{4}$ of different magnifications.
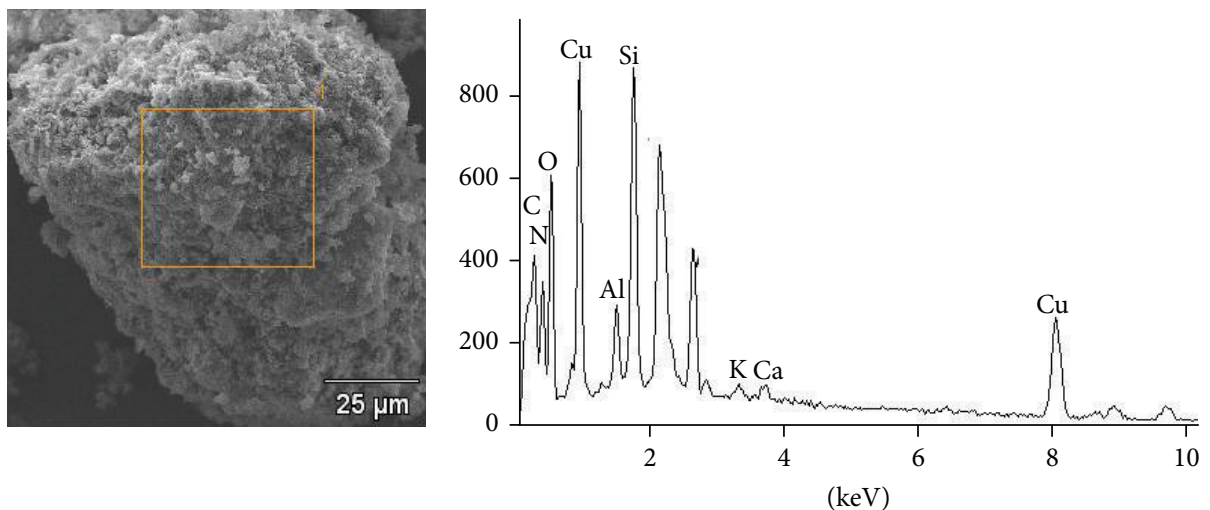

Figure 3: SEM image and EDAX of CuO/HCP-g- $\mathrm{C}_{3} \mathrm{~N}_{4}$.

unit in the hybrid composite increases to $798 \mathrm{~cm}^{-1}$ and a reduction in wavenumber for internal $\mathrm{Si}-\mathrm{O}(\mathrm{Si})$ and $\mathrm{Si}-\mathrm{O}(\mathrm{Al})$ stretch vibrations to $1081 \mathrm{~cm}^{-1}$.

3.4. Thermal Properties. Thermal gravimetric analysis of $\mathrm{CuO} / \mathrm{HCP}$ and the composite material was carried out to determine their thermal decomposition behaviour, which is depicted in Figures 6(a) and 6(b), respectively. However,
$\mathrm{CuO} / \mathrm{HCP}-\mathrm{g}-\mathrm{C}_{3} \mathrm{~N}_{4}$ depicts exceptional thermal stability compared to $\mathrm{CuO} / \mathrm{HCP}$ in overall temperature from 30 to $900^{\circ} \mathrm{C}$. The peak at $153.15^{\circ} \mathrm{C}$ for both materials as depicted in Figure 6(a) is ascribed to elimination of physically adsorbed water from the surface [36]. However, the weight loss peak at $258.01^{\circ} \mathrm{C}(\mathrm{CuO} / \mathrm{HCP})$ and $393.18^{\circ} \mathrm{C}$ (hybrid composite material) are also ascribed to exchangeable cations present in the HCP cavities and also the oxidation of volatile organic 


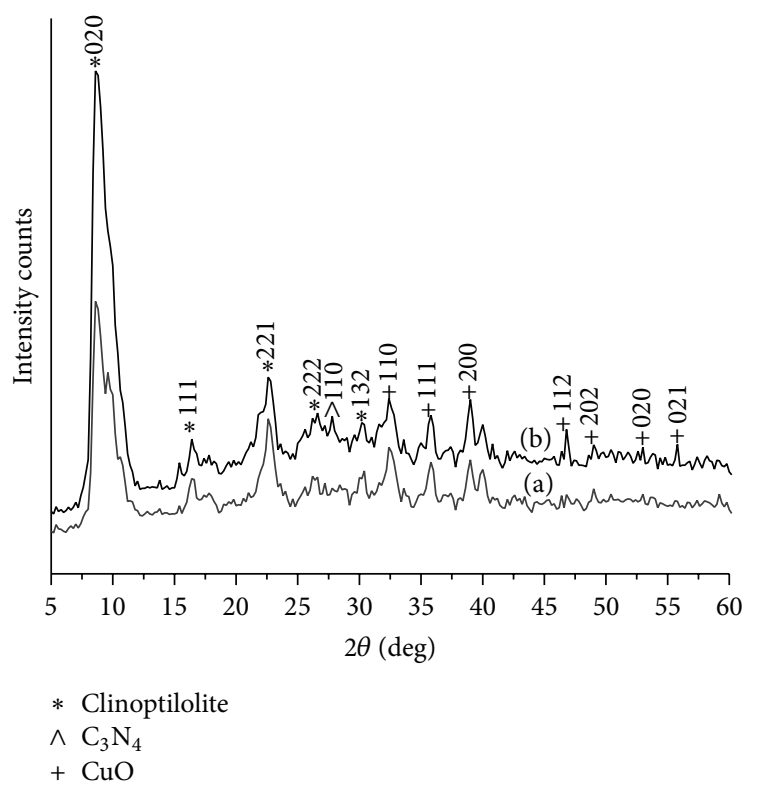

FIgure 4: XRD pattern at $2 \theta$ of (a) CuO/HCP-g- $\mathrm{C}_{3} \mathrm{~N}_{4}$ and (b) $\mathrm{CuO} / \mathrm{HCP}$.

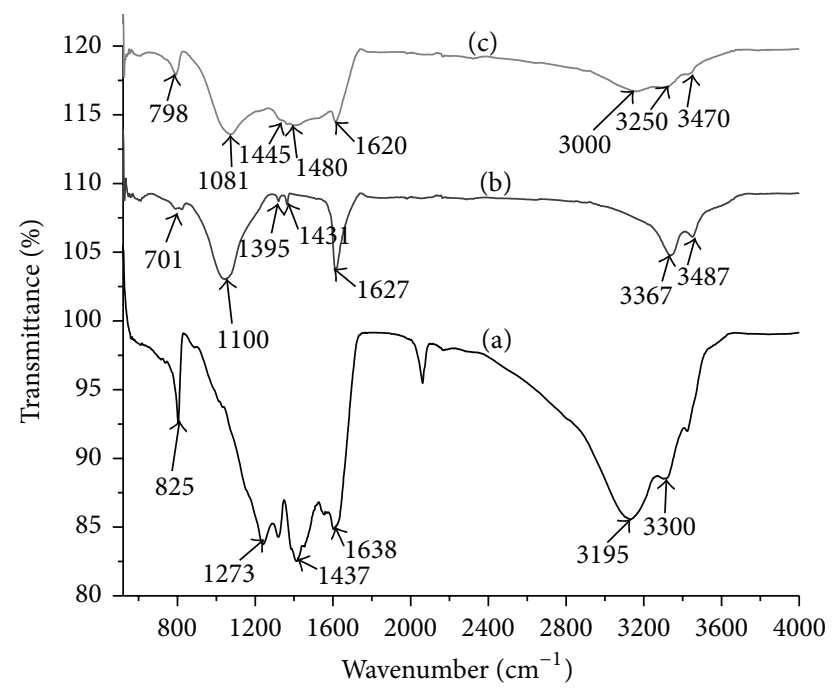

Figure 5: FTIR spectra of (a) $\mathrm{g}-\mathrm{C}_{3} \mathrm{~N}_{4}$ (b) $\mathrm{CuO} / \mathrm{HCP}$ and (c) $\mathrm{CuO} / \mathrm{HCP}-\mathrm{g}-\mathrm{C}_{3} \mathrm{~N}_{4}$.

species. The weight loss at 619.33 and $695.79^{\circ} \mathrm{C}$ in both materials is ascribed to phase transformation of metal oxide semiconductors on the surface of dealuminated clinoptilolite. The associated mass loss of the hybrid composite material was more pronounced than $\mathrm{CuO} / \mathrm{HCP}$ (Figure 6(a)) depicting successful dispersion of $\mathrm{CuO} / \mathrm{HCP}$ on $\mathrm{g}-\mathrm{C}_{3} \mathrm{~N}_{4}$ surface; this is coherent to similar observation in SEM image result of Figure 1.

Similar weight loss is noticeable with an endothermic peak in differential thermal analysis (DTA) result at $183^{\circ} \mathrm{C}$ for both materials (Figure 6(b)) that is due to loss of zeolitic water. The broad endothermic peak is prominent at $269.81^{\circ} \mathrm{C}$ for $\mathrm{CuO} / \mathrm{HCP}$, while the peaks at 321.03 and $400^{\circ} \mathrm{C}$ for the hybrid composite material are ascribed to elimination of residual zeolitic water and higher hydroxyls groups present on the surface of dealuminated clinoptilolite. The associated mass loss of hybrid composite material (21.65\%) is more than $\mathrm{CuO} / \mathrm{HCP}(7.88 \%)$ in the TGA (Figure 6(a)), with similar observations in the DTA result in Figure 6(b). Another broad endothermic peak for both materials at $583.78^{\circ} \mathrm{C}$ and $676.97^{\circ} \mathrm{C}$ is attributed to loss of residual coordinated water and the isolated $\mathrm{OH}$ groups. At this temperature, decomposition becomes steady and residual materials left are copper oxide and polymeric graphitic carbide. Mass weight loss of the hybrid composite material $(42.53 \%)$ was more than $\mathrm{CuO} / \mathrm{HCP}(35.18 \%)$.

3.5. Photocatalytic Reaction Mechanism. A possible photocatalytic reaction mechanism hereby proposed judging from the characterization analysis which in a long run will assist in understanding the photocatalytic efficiency of the hybrid composite material on organic contaminants. In the hybrid composite material, both $\mathrm{CuO}$ and $\mathrm{C}_{3} \mathrm{~N}_{4}$ metal semiconductors are in close contact and also separated by HCP. Under a visible light, the hybrid composite is excited and the generation of electron-hole pairs occurs, respectively (in the conduction and valence band), within the two different metal semiconductors. In close contact $\left(\mathbf{e}^{-}\right)$from $\mathrm{CuO}$ conduction band $\left(\mathrm{CB}\right.$ ) is transferred directly to $\mathrm{g}-\mathrm{C}_{3} \mathrm{~N}_{4} \mathrm{CB}$ (more negative Fermi), while transfer of $\mathbf{h}^{+}$from $\mathrm{g}-\mathrm{C}_{3} \mathrm{~N}_{4}$ valance band directly to $\mathrm{CuO} \mathrm{VB}$ (more positive Fermi) and there is a facilitation of electron-hole pair separation.

However, in terms of separated $\mathrm{CuO}$ and $\mathrm{g}-\mathrm{C}_{3} \mathrm{~N}_{4}$ dispersed on the surface of HCP, the pathway of e transfer between the two metal semiconductors is altered due to the presence of HCP as depicted in Scheme 1. HCP possesses intrinsic properties to act as electron acceptors from the excited molecule and also as electron donor [37] invariably within the system. Here $\mathbf{e}^{-}$from $\mathrm{CuO}(\mathrm{CB})$ is transferred to $\mathrm{HCP}$, where the latter facilitates interfacial charge transfers along $\mathrm{HCP}$ surface to $\mathrm{g}-\mathrm{C}_{3} \mathrm{~N}_{4}$. The same transfer of holes from g- $\mathrm{C}_{3} \mathrm{~N}_{4}$ to $\mathrm{CuO}$ occurs in the presence of $\mathrm{HCP}$, which results in an efficient charge separation by HCP. Also, the $g-\mathrm{C}_{3} \mathrm{~N}_{4}$ $\left(\mathbf{e}^{-}\right)$displays good reduction ability and the $\mathrm{CuO}\left(\mathbf{h}^{+}\right)$shows oxidizing power. The high reduction electron on the $g-\mathrm{C}_{3} \mathrm{~N}_{4}$ (CB) reacts with molecular $\mathrm{O}_{2}$ to form superoxide anions, which invariably oxidizes the organic pollutant. The hole in the $\mathrm{VB}$ of $\mathrm{CuO}$ reacts with water to generate hydroxyl radical which degrades the pollutant effectively. The hole in VB of $\mathrm{CuO}$ can also break down the organic pollutants directly due to high positive potential of $\mathrm{CuO}$.

Overall, HCP provides exceptional high surface area, good adsorption, and catalytic sites which favours the reaction process. HCP within the hybrid composite will act as an electron transporter, due to its high electron mobility of zeolites framework and ability to act as an electron acceptor or donor [38]. HCP in real sense accepts $\mathbf{e}^{-}$from the metal semiconductor (lower band gap) in a rapid manner and transfers the $\mathbf{e}^{-}$to other metal semiconductors (narrow band gap) and vice versa for hole transfer. In this same manner photogenerated electron-hole pairs are kept away from the metal oxide 


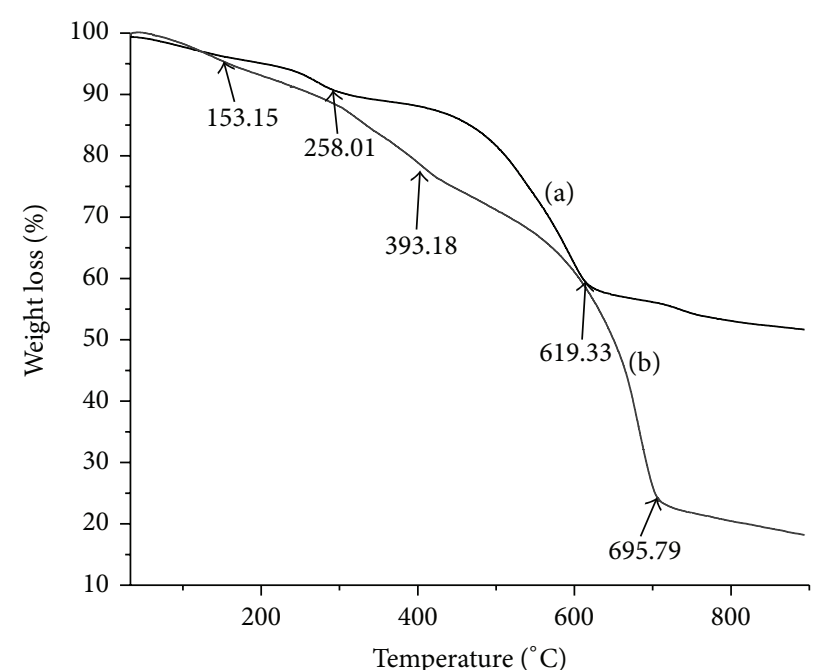

(a)

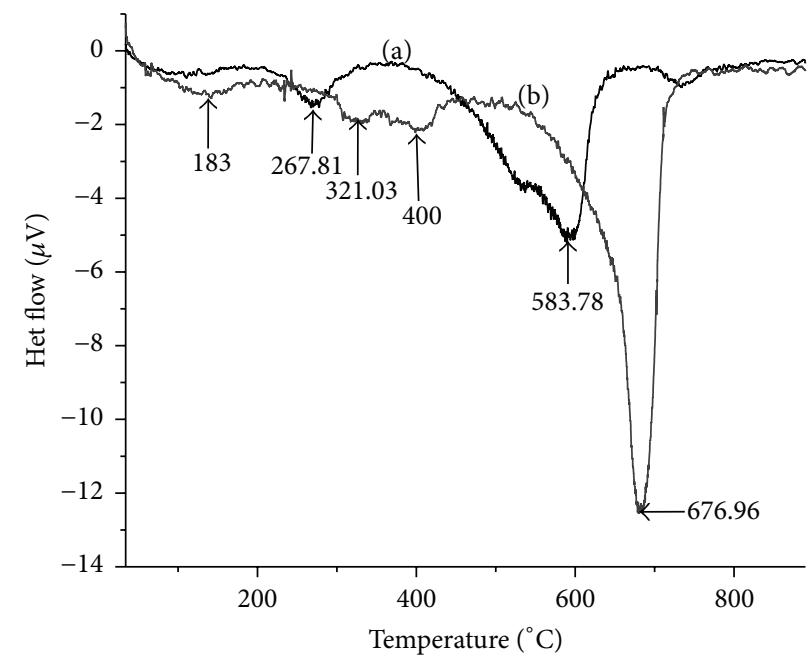

(b)

Figure 6: (a) TGA profile of (a) $\mathrm{CuO} / \mathrm{HCP}$ and (b) $\mathrm{CuO} / \mathrm{HCP}-\mathrm{g}-\mathrm{C}_{3} \mathrm{~N}_{4}$. (b) DTA profile of (a) $\mathrm{CuO} / \mathrm{HCP}$ and (b) CuO/HCP-g-C $\mathrm{N}_{4}$.

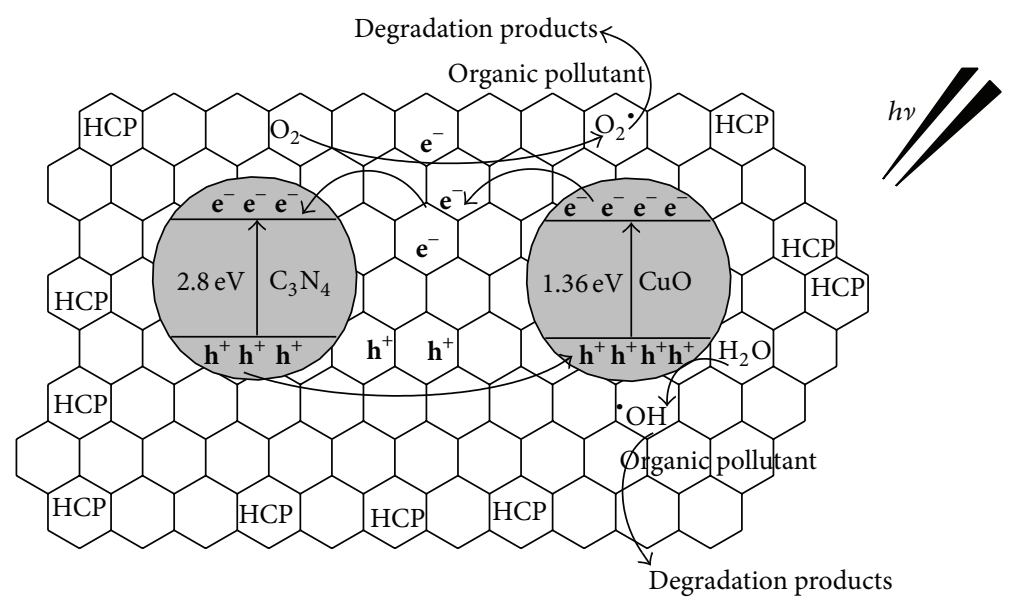

Scheme 1: Proposed reaction mechanism of separated electron-hole pair in $\mathrm{CuO} / \mathrm{HCP}-\mathrm{g}-\mathrm{C}_{3} \mathrm{~N}_{4}$ under visible light.

semiconductors, which invariably also reduces the recombination rate of photogenerated electron-hole pairs and improves overall catalytic activity of the hybrid composite material. The photocatalytic reaction mechanism highlighted in this study is consistent with the reported literature on the dispersion of mixed metal oxide semiconductor on mesoporous materials [23-26, 39].

\section{Conclusion}

$\mathrm{CuO} / \mathrm{HCP}-\mathrm{g}-\mathrm{C}_{3} \mathrm{~N}_{4}$ was synthesized through 2 facile routes, the precipitation method for $\mathrm{CuO} / \mathrm{HCP}$ and impregnation via ultrasonication method for the hybrid composite material $\left(\mathrm{CuO} / \mathrm{HCP}-\mathrm{g}-\mathrm{C}_{3} \mathrm{~N}_{4}\right)$. The surface morphology of the hybrid material revealed good homogenous dispersion of the metal oxide conductors within the textural of the dealuminated clinoptilolite. The thermal properties of the hybrid composite material depict excellent thermal stability more than $\mathrm{CuO} /$ HCP. The contribution of mixed metal oxide semiconductors within the hybrid composite assists to reduce the recombination rate of photogenerated electron-hole pairs, which invariably can facilitate enhanced photocatalytic activity. HCP in the hybrid composite material acts as electron transporter; it also reduces recombination rate and improves overall catalytic activity of the photocatalyst material. $\mathrm{CuO} / \mathrm{HCP}-\mathrm{g}-$ $\mathrm{C}_{3} \mathrm{~N}_{4}$ is a promising hybrid composite material for environmental purification and also for generation of clean energy from water splitting application.

\section{Conflict of Interests}

The authors declare that there is no conflict of interests regarding the publication of this paper. 


\section{Acknowledgments}

The authors acknowledge Vaal University of Technology for funding. The authors also thank Mr. Seth Apollo for the provision of Clinoptilolite. The Chemistry Department, University of Fort Hare, is greatly appreciated.

\section{References}

[1] J. Tang, Z. Zou, J. Yin, and J. Ye, "Photocatalytic degradation of methylene blue on $\mathrm{CaIn}_{2} \mathrm{O}_{4}$ under visible light irradiation," Chemical Physics Letters, vol. 382, no. 1-2, pp. 175-179, 2003.

[2] $\mathrm{C}$. $\mathrm{Hu}$ and $\mathrm{H}$. Teng, "Influence of structural features on the photocatalytic activity of $\mathrm{NaTaO}_{3}$ powders from different synthesis methods," Applied Catalysis A: General, vol. 331, no. 1, pp. 44-50, 2007.

[3] Y. Yamashita, K. Yoshida, M. Kakihana, S. Uchida, and T. Sato, "Polymerizable complex synthesis of $\mathrm{RuO}_{2} / \mathrm{BaTi}_{4} \mathrm{O}_{9}$ photocatalysts at reduced temperatures: factors affecting the photocatalytic activity for decomposition of water," Chemistry of Materials, vol. 11, no. 1, pp. 61-66, 1999.

[4] Z. Zhou, J. Ye, and H. Arakawa, "Surface characterization of nanoparticles of $\mathrm{NiO}_{x} / \mathrm{In}_{0.9} \mathrm{Ni}_{0.1} \mathrm{TaO}_{4}$ : effects on photocatalytic activity," The Journal of Physical Chemistry B, vol. 106, no. 51, pp. 13098-13101, 2002.

[5] S. Tokunaga, H. Kato, and A. Kudo, "Selective preparation of monoclinic and tetragonal $\mathrm{BiVO}_{4}$ with scheelite structure and their photocatalytic properties," Chemistry of Materials, vol. 13, no. 12, pp. 4624-4628, 2001.

[6] F. F. Abdi and R. van de Krol, "Nature and light dependence of bulk recombination in Co-Pi-Catalyzed $\mathrm{BiVO}_{4}$ photoanodes," The Journal of Physical Chemistry C, vol. 116, no. 17, pp. 93989404, 2012.

[7] W. J. Jo, J. W. Jang, K. J. Kong et al., "Phosphate doping into monoclinic $\mathrm{BiVO}_{4}$ for enhanced photoelectrochemical water oxidation activity," Angewandte Chemie, vol. 51, no. 13, pp. 31473151, 2012.

[8] J. Z. Yang, J. W. Yu, J. Fan, D. P. Sun, W. H. Tang, and X. J. Yang, "Biotemplated preparation of CdS nanoparticles/bacterial cellulose hybrid nanofibers for photocatalysis application," Journal of Hazardous Materials, vol. 189, no. 1-2, pp. 377-383, 2011.

[9] Z. J. Zhang, W. Z. Wang, M. Shang, and W. Z. Yin, "Inducing photocatalysis by visible light beyond the absorption edge: effect of up conversion agent on the photocatalytic activity of $\mathrm{Bi}_{2} \mathrm{WO}_{6}$," Applied Catalysis B: Environmental, vol. 177, no. 1-2, pp. 1013-1018, 2010.

[10] Y. Zhang, G. Chang, S. Liu et al., "Microwave-assisted, environmentally friendly, one-pot preparation of Pd nanoparticles/graphene nanocomposites and their application in electrocatalytic oxidation of methanol," Catalysis Science \& Technology, vol. 1, no. 9, pp. 1636-1640, 2011.

[11] W. S. Hummers Jr. and R. E. Offeman, "Preparation of graphitic oxide," Journal of the American Chemical Society, vol. 80, no. 6, p. 1339, 1958.

[12] S. Bai and X. Shen, "Graphene-inorganic nanocomposites," RSC Advances, vol. 2, no. 1, pp. 64-98, 2012.

[13] K. Zhou, R. Wang, B. Xu, and Y. Li, "Synthesis, characterization and catalytic properties of $\mathrm{CuO}$ nanocrystals with various shapes," Nanotechnology, vol. 17, no. 15, pp. 3939-3943, 2006.

[14] X. P. Gao, J. L. Bao, G. L. Pan et al., "Preparation and electrochemical performance of polycrystalline and single crystalline
$\mathrm{CuO}$ nanorods as anode materials for Li ion battery," Journal of Physical Chemistry B, vol. 108, no. 18, pp. 5547-5551, 2004.

[15] P. Ameta, A. Kumar, R. Ameta, and R. K. Malkani, "A comparative study of photocatalytic activity of some coloured semiconducting oxides," Iranian Journal of Chemistry and Chemical Engineering, vol. 29, no. 2, pp. 43-48, 2010.

[16] D. A. Fungaro, L. C. Grosche, A. S. Pinheiro, J. C. Izidoro, and S. I. Borrely, "Adsorption of methylene blue from aqueous solution on zeolitic material for color and toxicity removal," The Electronic Journal of Chemistry, vol. 2, no. 3, pp. 235-247, 2010.

[17] N. Nasuha, H. Z. Zurainan, H. I. Maarof, N. A. Zubir, and N. Amri, "Effect of cationic and anionic dye adsorption from aqueous solution by using chemically modified papaya seed," in Proceedings of the International Conference on Environment Science and Engineering, vol. 8, pp. 50-54, 2011.

[18] X. C. Wang, K. Maeda, A. Thomas et al., "A metal-free polymeric photocatalyst for hydrogen production from water under visible light," Nature Materials, vol. 8, no. 1, pp. 76-80, 2009.

[19] S. C. Yan, Z. S. Li, and Z. G. Zou, "Photodegradation performance of $\mathrm{g}-\mathrm{C}_{3} \mathrm{~N}_{4}$ fabricated by directly heating melamine," Langmuir, vol. 25, no. 17, pp. 10397-10401, 2009.

[20] F. Dong, Y. Sun, L. Wu, M. Fu, and Z. Wu, "Facile transformation of low cost thiourea into nitrogen-rich graphitic carbon nitride nanocatalyst with high visible light photocatalytic performance," Catalysis Science \& Technology, vol. 2, no. 7, pp. 13321335, 2012.

[21] L. Ge and C. Han, "Synthesis of MWNTs/g- $\mathrm{C}_{3} \mathrm{~N}_{4}$ composite photocatalysts with efficient visible light photocatalytic hydrogen evolution activity," Applied Catalysis B: Environmental, vol. 117-118, no. 18, pp. 268-274, 2012.

[22] L. Ge, C. Han, and J. Liu, "In situ synthesis and enhanced visible light photocatalytic activities of novel PANI-g- $\mathrm{C}_{3} \mathrm{~N}_{4}$ composite photocatalysts," Journal of Materials Chemistry, vol. 22, no. 23, pp. 11843-11850, 2012.

[23] J. Wang, P. Wang, Y. Cao et al., "A high efficient photocatalyst $\mathrm{Ag}_{3} \mathrm{VO}_{4} / \mathrm{TiO}_{2} /$ graphene nanocomposite with wide spectral response," Applied Catalysis B: Environmental, vol. 136-137, pp. 94-102, 2013.

[24] Y. Hou, F. Zuo, Q. Ma, C. Wang, L. Bartels, and P. Feng, “ $\mathrm{Ag}_{3} \mathrm{PO}_{4}$ oxygen evolution photocatalyst employing synergistic action of $\mathrm{Ag} / \mathrm{AgBr}$ nanoparticles and graphene sheets," The Journal of Physical Chemistry C, vol. 116, no. 38, pp. 20132-20139, 2012.

[25] B. Wang, Q. Sun, S. Liu, and Y. Li, "Synergetic catalysis of $\mathrm{CuO}$ and graphene additives on $\mathrm{TiO}_{2}$ for photocatalytic water splitting," International Journal of Hydrogen Energy, vol. 38, no. 18, pp. 7232-7240, 2013.

[26] Z.-D. Meng, L. Zhu, K. Ullah, S. Ye, Q. Sun, and W.-C. Oh, "Enhanced visible light photocatalytic activity of $\mathrm{Ag}_{2} \mathrm{~S}$-graphene/ $/ \mathrm{TiO}_{2}$ nanocomposites made by sonochemical synthesis," Chinese Journal of Catalysis, vol. 34, no. 8, pp. 1527-1533, 2013.

[27] S. O. Saheed, S. J. Modise, and A. M. Sipamla, “ $\mathrm{TiO}_{2}$ supported clinoptilotile: characterization and optimization of operational parameters for methyl orange removal," Advanced Materials Research, vol. 781-784, pp. 2249-2252, 2013.

[28] S. O. Sanni and O. G. Idemudia, "Synthesis and characterization of rhodium doped on $\mathrm{TiO}_{2} / \mathrm{HCP}$ for eenhanced photocatalytic performance on pentachlorophenol," Journal of Nanomaterials, vol. 2014, Article ID 287493, 8 pages, 2014.

[29] D. P. Volanti, D. Keyson, L. S. Cavalcante et al., "Synthesis and characterization of $\mathrm{CuO}$ flower-nanostructure processing by a domestic hydrothermal microwave," Journal of Alloys and Compounds, vol. 459, no. 1-2, pp. 537-542, 2008. 
[30] A. Nezamzadeh-Ejhieh and Sh. Hushmandrad, "Solar photodecolorization of methylene blue by $\mathrm{CuO} / \mathrm{X}$ zeolite as a heterogeneous catalyst," Applied Catalysis A: General, vol. 388, no. 1-2, pp. 149-159, 2010.

[31] S. Matsumoto, E.-Q. Xie, and F. Izumi, "On the validity of the formation of crystalline carbon nitrides, $\mathrm{C}_{3} \mathrm{~N}_{4}$, Diamond and Related Materials, vol. 8, no. 7, pp. 1175-1182, 1999.

[32] X. Li, J. Zhang, L. Shen et al., "Preparation and characterization of graphitic carbon nitride through pyrolysis of melamine," Applied Physics A: Materials Science and Processing, vol. 94, no. 2, pp. 387-392, 2009.

[33] Y. Zhao, Z. Liu, W. Chu et al., "Large-scale synthesis of nitrogenrich carbon nitride microfibers by using graphitic carbon nitride as precursor," Advanced Materials, vol. 20, no. 9, pp. 1777-1781, 2008.

[34] H. Faghihian, M. Talebi, and M. Pirouzi, "Adsorption of nitrogen from natural gas by clinoptilolite," Journal of the Iranian Chemical Society, vol. 5, no. 3, pp. 394-399, 2008.

[35] M. Brazlauskas and S. Kitrys, "Synthesis and properties of $\mathrm{CuO} /$ Zeolite sandwich type adsorbent-catalysts," Chinese Journal of Catalysis, vol. 29, no. 1, pp. 25-30, 2008.

[36] W. Guoxiu, Y. Juan, P. Jinsoo et al., "Facile synthesis and characterization of graphene nanosheets," The Journal of Physical Chemistry C, vol. 112, no. 22, pp. 8192-8195, 2008.

[37] M. Matsuoka and M. Anpo, "Local structures, excited states, and photocatalytic reactivities of highly dispersed catalysts constructed within zeolites," Journal of Photochemistry and Photobiology C: Photochemistry Reviews, vol. 3, no. 3, pp. 225252, 2003.

[38] A. Corma and H. Garcia, "Zeolite-based photocatalysts," Chemical Communications, no. 13, pp. 1443-1459, 2004.

[39] Y. Fang, R. Wang, G. Jiang et al., " $\mathrm{CuO} / \mathrm{TiO}_{2}$ nanocrystals grown on graphene as visible-light responsive photocatalytic hybrid materials," Bulletin of Materials Science, vol. 35, no. 4, pp. 495499, 2012. 

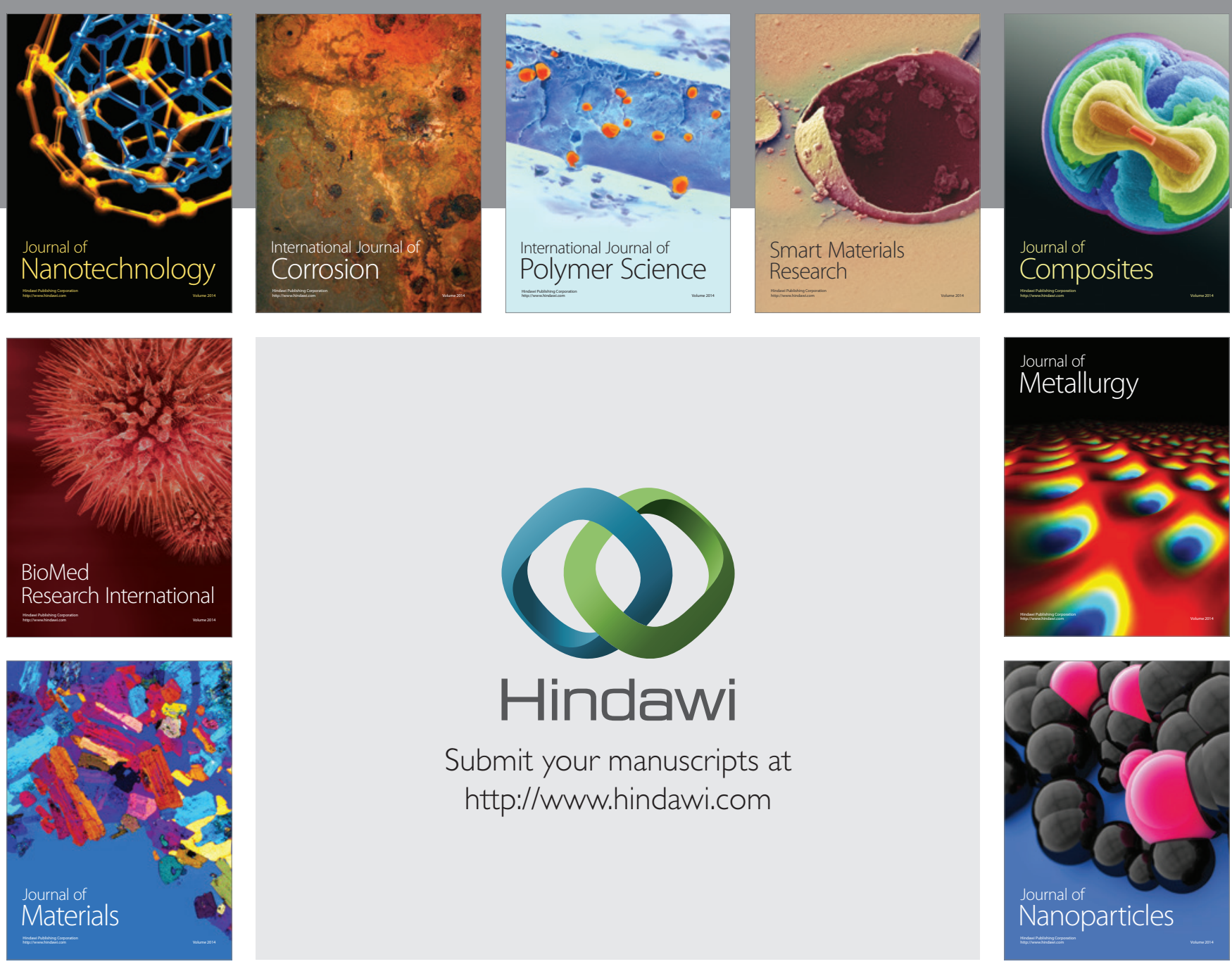

Submit your manuscripts at http://www.hindawi.com
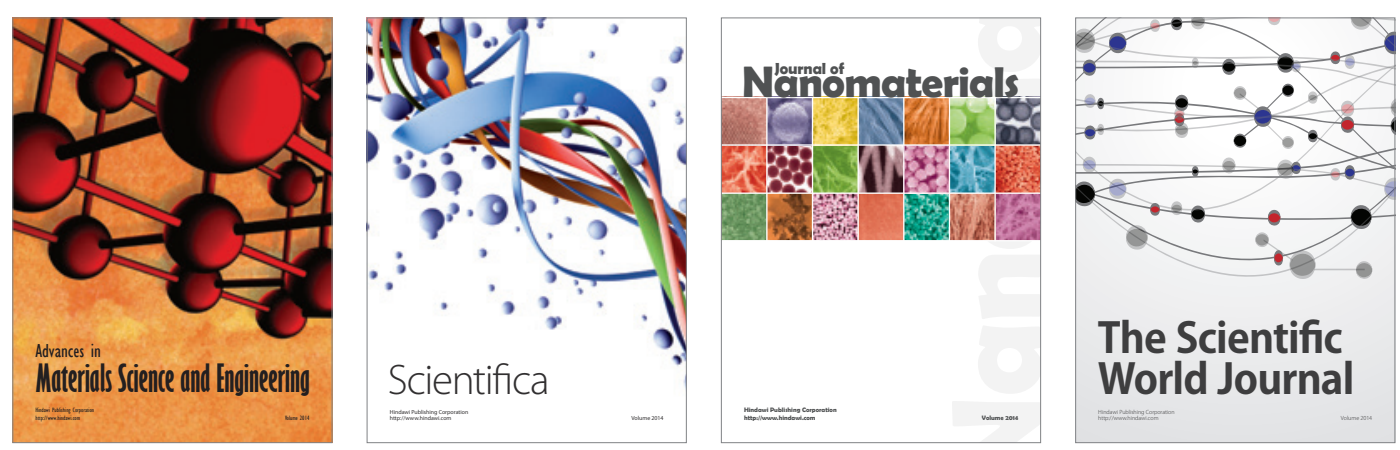

\section{The Scientific World Journal}
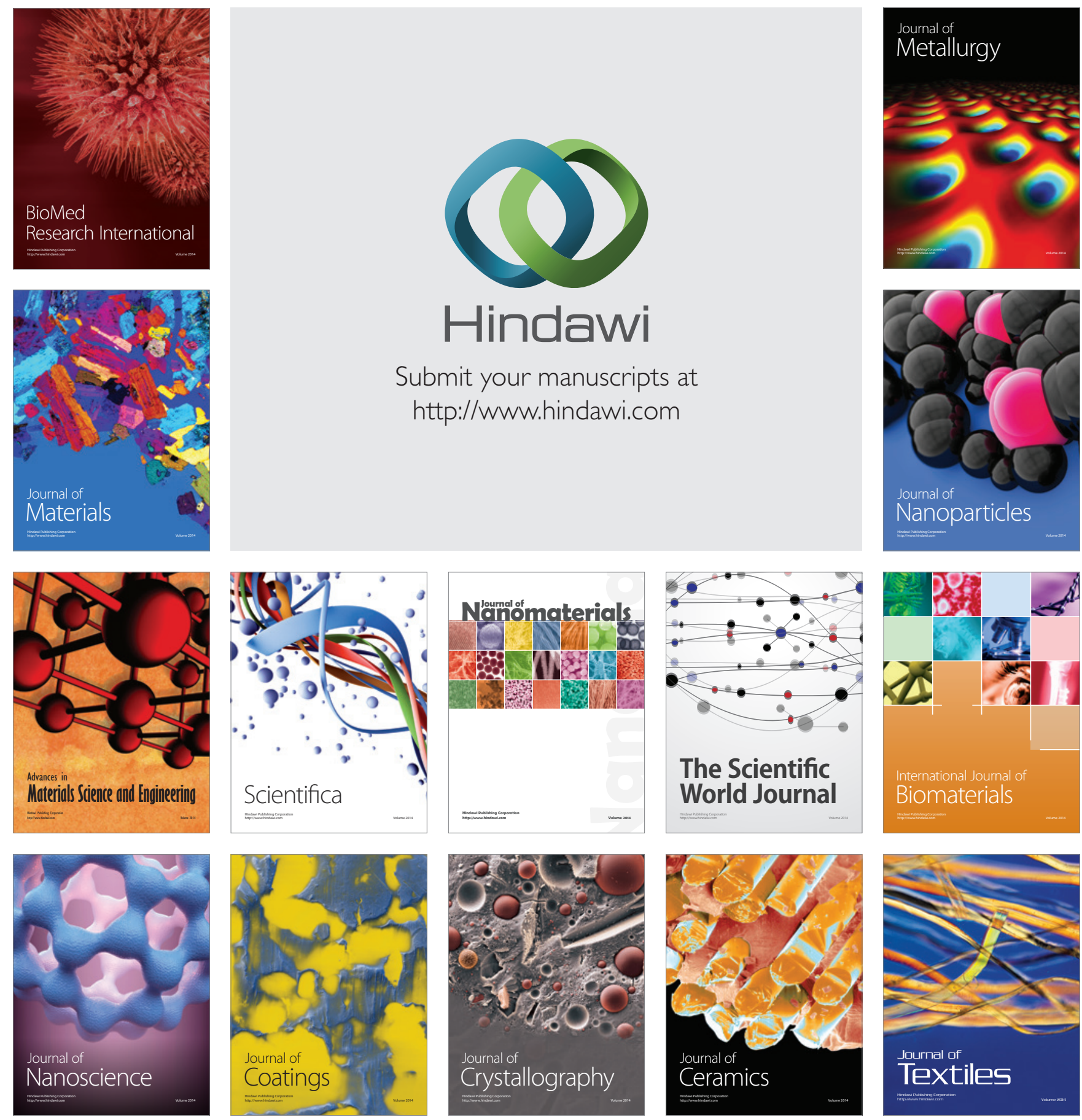